\title{
Burden and associated factors for caregivers of the elderly in a developing country
}

\author{
S. Sabzwari, ${ }^{7}$ A. Munir Badini ${ }^{1}$ Z. Fatmi, ${ }^{2}$ T. Jamali' ${ }^{2}$ S. Shah ${ }^{3}$
}

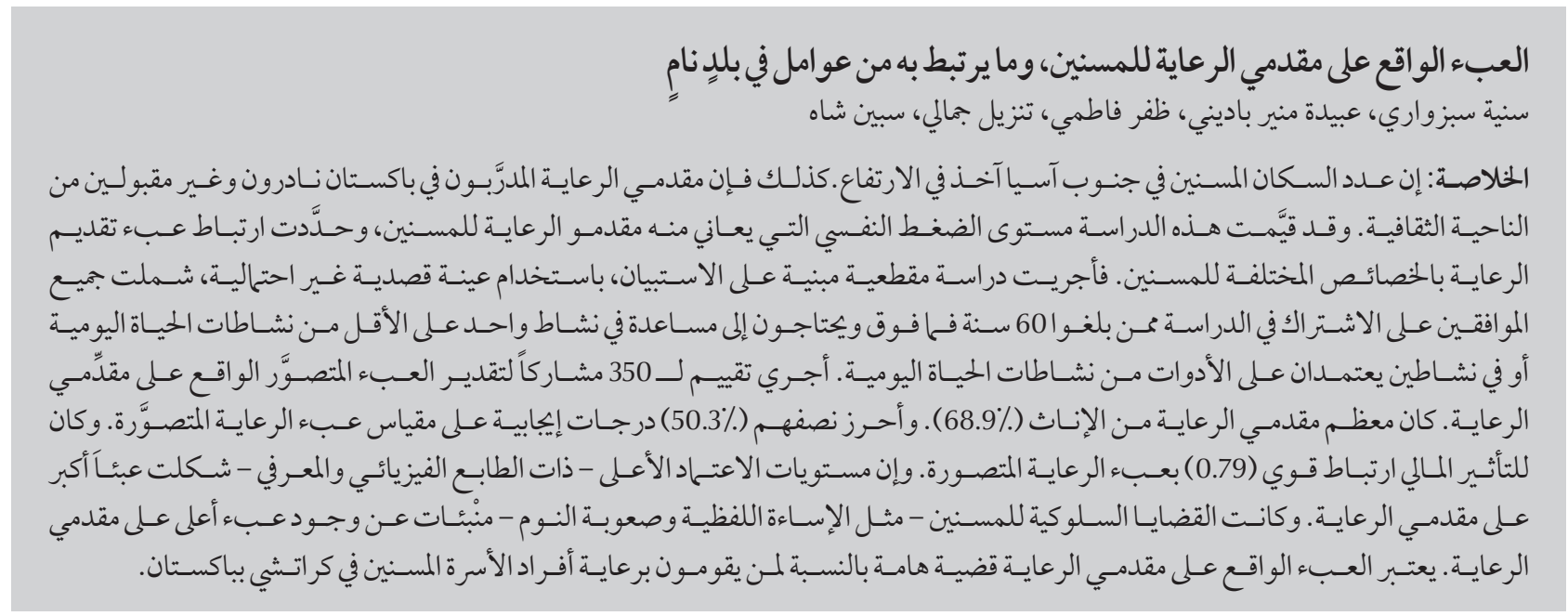

ABSTRACT The elderly population in South Asia is growing. In Pakistan trained caregivers are scarce and culturally not acceptable. This study assessed the level of stress experienced by caregivers of the elderly and determined the association of care giving burden with different characteristics of the elderly. A cross-sectional, questionnaire based study was conducted using nonprobability purposive sampling. All consenting participants aged 60 years and above needing help with at least one activity of daily living or two instrumental activities of daily living were included. 350 participants were assessed for perceived care giver burden. Care providers were mostly female (68.9\%). Half (50.3\%) of the caregivers had a positive score on a perceived care burden scale. Financial impact had a strong correlation (0.79) with perceived caregiver burden. Higher dependency levels of a physical and cognitive nature posed greater burden on caregivers. Behavioural issues of the elderly such as verbal abuse and difficulty sleeping were predictors of a higher caregiver burden. Caregiver burden is a significant issue for those caring for elderly family members in Karachi, Pakistan.

\section{Fardeau et facteurs associés pour les aidants de personnes âgées dans un pays en développement}

RÉSUMÉ La population âgée d'Asie du Sud-Est connaît une augmentation. Au Pakistan, les personnels soignants formés sont rares et non acceptés d'un point de vue culturel. La présente étude avait pour objectif d'évaluer le niveau de stress des aidants de personnes âgées et de déterminer l'association entre le fardeau de soins et différentes caractéristiques propres aux personnes âgées. Une étude transversale, reposant sur un questionnaire, a été conduite en recourant à un échantillonnage non probabiliste par choix raisonné. Toutes les personnes consentantes âgées de 60 ans et plus requérant une aide pour au moins une activité de la vie quotidienne ou deux activités instrumentales de la vie quotidienne ont été incluses. Le fardeau perçu par les aidants a été évalué chez 350 participants. Les dispensateurs de soins étaient majoritairement des femmes (68,9\%). La moitié (50,3\%) des aidants obtenaient des scores élevés sur l'échelle d'évaluation du fardeau de soins. L'impact financier avait une forte corrélation $(0,79)$ avec la perception du fardeau de soins. Des niveaux de dépendance physique ou cognitive plus élevés rajoutaient au fardeau supporté par les aidants. Les problèmes comportementaux des personnes âgées tels que des insultes verbales ou des troubles du sommeil constituaient d'importants indicateurs d'un fardeau plus lourd. Le fardeau des aidants est un problème de taille pour les personnes qui prennent soin de membres âgés de leurs familles à Karachi, au Pakistan.

${ }^{1}$ Department of Family Medicine, ${ }^{2}$ Department of Community Health Sciences, Aga Khan University, Karachi, Pakistan (correspondence to Saniya Sabzwari: Saniya.sabzwari@aku.edu). ${ }^{3}$ End TB Project, Interactive Research and Development, Shahrah-e-Faisal, Karachi, Pakistan Received: 21/09/15; accepted: 06/06/16 


\section{Introduction}

The elderly population of South Asia is seeing an unprecedented rise. According to the $2013 \mathrm{WHO}$ data repository (1), $6.5 \%$ of the Pakistani population is over the age of 60. By 2050, the elderly are expected to constitute $15 \%$ of the total population (2). Longer life spans are, however, frequently associated with illnesses that cause disability and dependence.

According to the World Health Organization, older people residing in lowincome countries have higher disability rates, and woman are at greater risk than men (3). Data on disability from Pakistan are scarce and do not include common impairments seen in the elderly, such as dementia and osteoarthritis.

In Pakistan, traditional family values, including revering elders, are still held, and providing care and support to the elderly is considered a social norm and a moral duty for family members. In the past few decades, however, joint family systems have shifted rapidly to nuclear families (i.e. parents and their dependent children) (4), so that elderly family members are often cared for by one caregiver rather than multiple relatives in an extended family (5). Moreover, in contrast to the western world, where professional caregiving is the norm, trained caregivers are scarce, expensive and at times unacceptable. A handful of nursing homes exists, which is not a culturally acceptable solution for caring for the elderly (5). This changing socio-cultural system is bound to make the burden on caregivers an issue that will require attention at all levels, as the physical and psychosocial effects of caregiving are well documented $(6,7)$.

We conducted a literature review of studies on caregivers and determined the factors responsible for their burden. Most studies identified the family as the primary caregivers for elderly family members. One regional study indicated that spouses were most adversely affected by a cognitive decline in a care receiver (8). A study of caregivers for patients with Alzheimer disease revealed that caregivers of male patients experienced the greatest burden. The burden of caregivers in joint families did not differ from those in nuclear families (9).

Limited national data were available on the characteristics of caregivers and their burden. Anecdotal evidence suggests that most caregiving is provided by families and mostly by women. We assessed the burden experienced by carers of the elderly in our setting and determined the factors associated with the burden of care provision.

\section{Methods}

\section{Study design}

We conducted a cross-sectional study of a convenience sample in 2013, in which research associates visited the homes of a local community in Karachi to collect data.

\section{Sample size}

The sample size was calculated with WHO software (version 2.0) (10). As no local data were available on the burden of caregivers in Pakistan, a proportion of 0.50 was used to achieve maximum variance with an error bound of $6 \%$ and a $5 \%$ significance level. The final sample size was calculated to be 267. After inflation by $10 \%$ for non-responders, the sample size was estimated to be approximately 300 .

\section{Inclusion criteria}

All consenting people aged 60 years and above who required help with at least one or more of the activities of daily living (ADLs) or two or more of the instrumental activities of daily living (IADLs) were included. They are referred to below as "care recipients".

\section{Exclusion criteria}

Paid caregivers and elderly patients residing in nursing homes were excluded from the study, as these are not typical solutions for caregiving in Pakistan.

\section{Definitions}

A "caregiver" was defined as an adult 18 years of age or older, either a family member or a voluntary worker, who provides help with ADLs, health care and financial and social matters to care recipients.

"Caregiver burden" was defined as physical, psychological, social and financial problems that might be experienced by family members caring for impaired older adults (8).

ADLs include dressing, eating, walking, toileting and showering, and IADLs include shopping, managing money, using a telephone, arranging transport, housekeeping, preparing meals and taking medication.

\section{Ethical approval}

Ethical approval was obtained from the university ethics committee. Detailed, explicit consent was obtained from all participants. All questionnaires were coded, and data were entered with these codes to ensure participant confidentiality.

\section{Data collection tools}

The demographics of care recipients and caregivers, the characteristics of care receivers (ADLs, IADLs, co-morbid conditions, behavioural problems) and the duration and type of caregiving were obtained from answers to a questionnaire, which was translated into Urdu and then back-translated into English. A pilot study was conducted on $10 \%$ of the total sample size, and the results were used to modify the questionnaire.

Caregiver burden was measured on a five-point Likert scale of scores on a validated 12-item "perceived caregiver burden scale" used in regional studies (11). This three-part scale assesses the 
impact on finances, abandonment by the extended family and sense of entrapment as experienced by the caregiver. (See Annex 1. Permission to use this scale was obtained from the author). The Cronbach's alpha for each subscale was greater than 0.77 .

\section{Data collection procedure}

Respondents were approached during home assessments conducted in local communities in Karachi. Households with elderly residents were identified from community volunteers, and research associates visited the identified homes to administer the questionnaire to each of the caregivers in the household. The participating families were given feedback on caregiver stress.

\section{Statistical analysis}

All data were entered into Epidata 3.1 and analysed with SPSS version 19. Proportions were generated for the categorical variables gender, number of care recipients, behaviour, ADLs, IADLs and presence of co-morbid conditions. Mean and standard deviation were reported for continuous variables such as the age of the caregiver and recipient and the duration of caregiving. The outcome variable was the caregiver burden. The mean scores of the answers to questions on the burden of caregivers were calculated, and the scores were then split from the median to form a binary variable (burdened/not burdened). Chi-squared tests were used to assess the associations between ADLs, IADLs and the burden on caregivers, with a significance level of 0.05 .

\section{Results}

The socio-demographic characteristics of caregivers and care recipients, ADLs and IADLs and co-morbid illnesses are listed in Table 1. The mean age of caregivers was $47.23 \pm 15.5$ years. Most of the caregivers were female (241; $68.9 \%)$, married $(311 ; 88.9 \%)$, daughters-in-law $(119 ; 34 \%)$ and spouses (94; 26.8\%). More than one third had secondary education ( $139 ; 39.7 \%)$. The mean age of the care recipients was
$71.1 \pm 10.1$ years, and most were female (208; 59.4\%). Caregivers provided assistance for ADLs like dressing (57; $16.3 \%)$, bathing $(60 ; 17.2 \%)$ and walking $(160 ; 45.7 \%)$. Assistance for IADLs was mainly for shopping (279; 79.9\%), preparing meals $(226 ; 64.6 \%)$ and using a telephone $(163 ; 46.6 \%)$. One third of care recipients (35.4\%) required help in managing money, and 33.3\% were helped in taking medication. Only $37.2 \%$ were fully mobile, while $45.7 \%$ required assistance from the caregiver; $13.7 \%$ had an assisted device, and 3.4\% were bedridden.

The co-morbid illnesses of care recipients included osteoarthritis (220; $63 \%)$, hypertension $(169 ; 48.4 \%)$ and diabetes $(105 ; 30.1 \%)$. Memory loss was reported in 131 (37.4\%). Agitation was the commonest behavioural problem (183; 52.3\%). Approximately half the caregivers had a positive score for perceived care burden.

The association between ADLs and caregiver burden is shown in Table 2. Caregivers who provided help in

\begin{tabular}{|c|c|c|c|c|c|c|}
\hline \multicolumn{7}{|c|}{ Annex 1. Perceived caregiver burden } \\
\hline \multicolumn{2}{|c|}{ Subscale 1: Imapct on finances } & \multirow[t]{2}{*}{1} & \multirow[t]{2}{*}{2} & \multirow[t]{2}{*}{3} & \multirow[t]{2}{*}{4} & \multirow[t]{2}{*}{5} \\
\hline 1 & $\begin{array}{l}\text { My financial resources are adequate to pay for } \\
\text { things that are required for caregiving }\end{array}$ & & & & & \\
\hline 2 & $\begin{array}{l}\text { It is difficult to pay for the elderly person's health } \\
\text { needs and services }\end{array}$ & & & & & \\
\hline 3 & $\begin{array}{l}\text { Caring for the elderly person has put a financial } \\
\text { strain on the family }\end{array}$ & & & & & \\
\hline 4 & $\begin{array}{l}\text { If I could afford it, I would find some other way } \\
\text { to care for the elderly person }\end{array}$ & & & & & \\
\hline \multicolumn{7}{|c|}{ Subscale 2: Abandonment by extended family } \\
\hline 5 & $\begin{array}{l}\text { Since caring for the elderly person, I feel that my } \\
\text { family has abandoned me }\end{array}$ & & & & & \\
\hline 6 & $\begin{array}{l}\text { It is very difficult to get help from my family in } \\
\text { taking care of the elderly person }\end{array}$ & & & & & \\
\hline 7 & $\begin{array}{l}\text { Others have left caring for the elderly person to } \\
\text { me }\end{array}$ & & & & & \\
\hline \multicolumn{7}{|c|}{ Subscale 3: Sense of entrapment } \\
\hline 8 & $\begin{array}{l}\text { Since caring for the elderly person, it seems like I } \\
\text { am tired all the time }\end{array}$ & & & & & \\
\hline 9 & $\begin{array}{l}\text { I feel overwhelmed by the problems I have } \\
\text { caring for the elderly person }\end{array}$ & & & & & \\
\hline 10 & $\begin{array}{l}\text { I get very discouraged with caring for the elderly } \\
\text { person }\end{array}$ & & & & & \\
\hline 11 & $\begin{array}{l}\text { Since caring for the elderly person, sometimes I } \\
\text { hate the way life has turned out }\end{array}$ & & & & & \\
\hline 12 & $\begin{array}{l}\text { At this time in my life, I don't think I should be } \\
\text { caring for the elderly person }\end{array}$ & & & & & \\
\hline
\end{tabular}

1- strongly disagree, 2- disagree, 3- agree, 4- strongly agree, 5- I don't know 


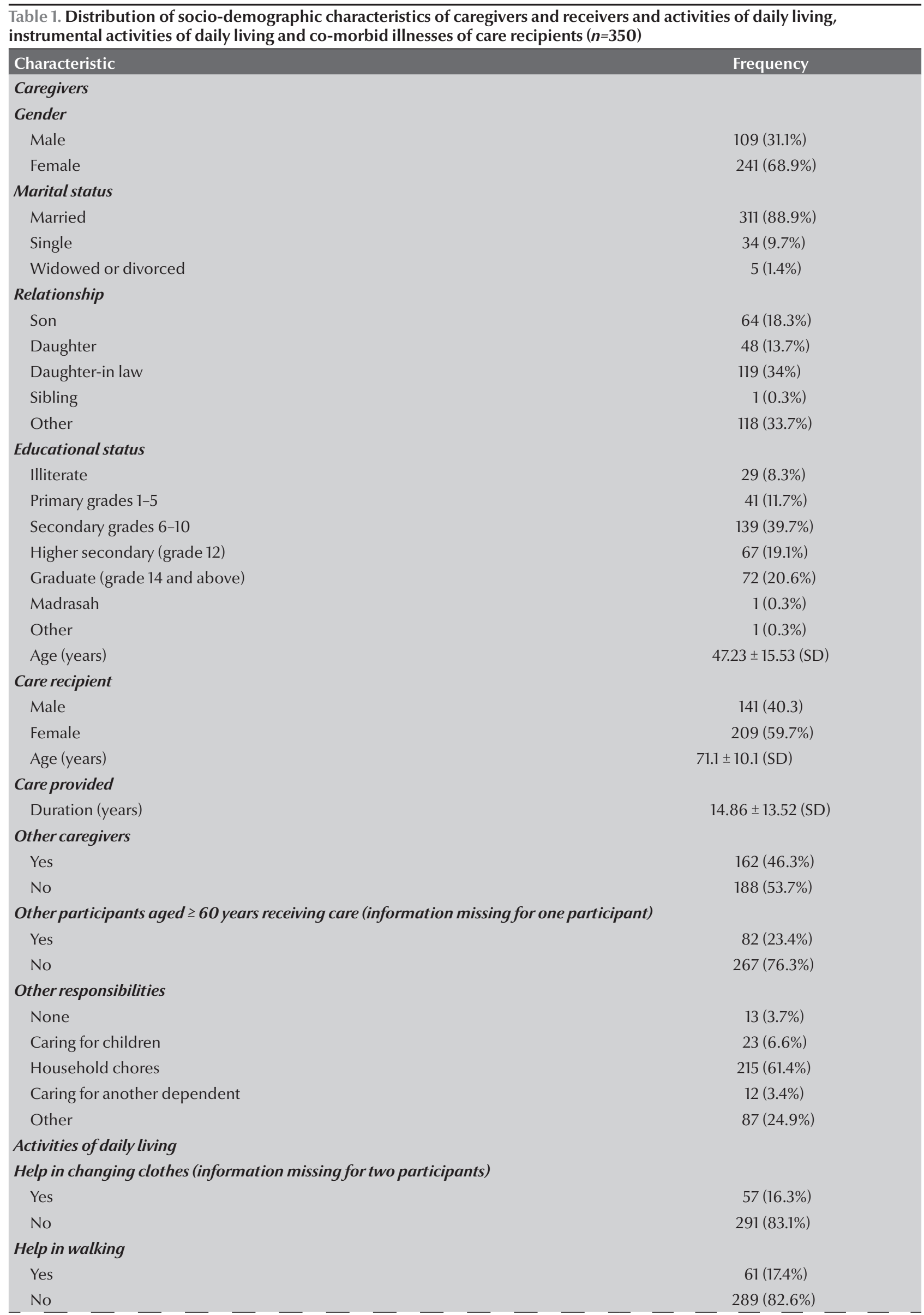




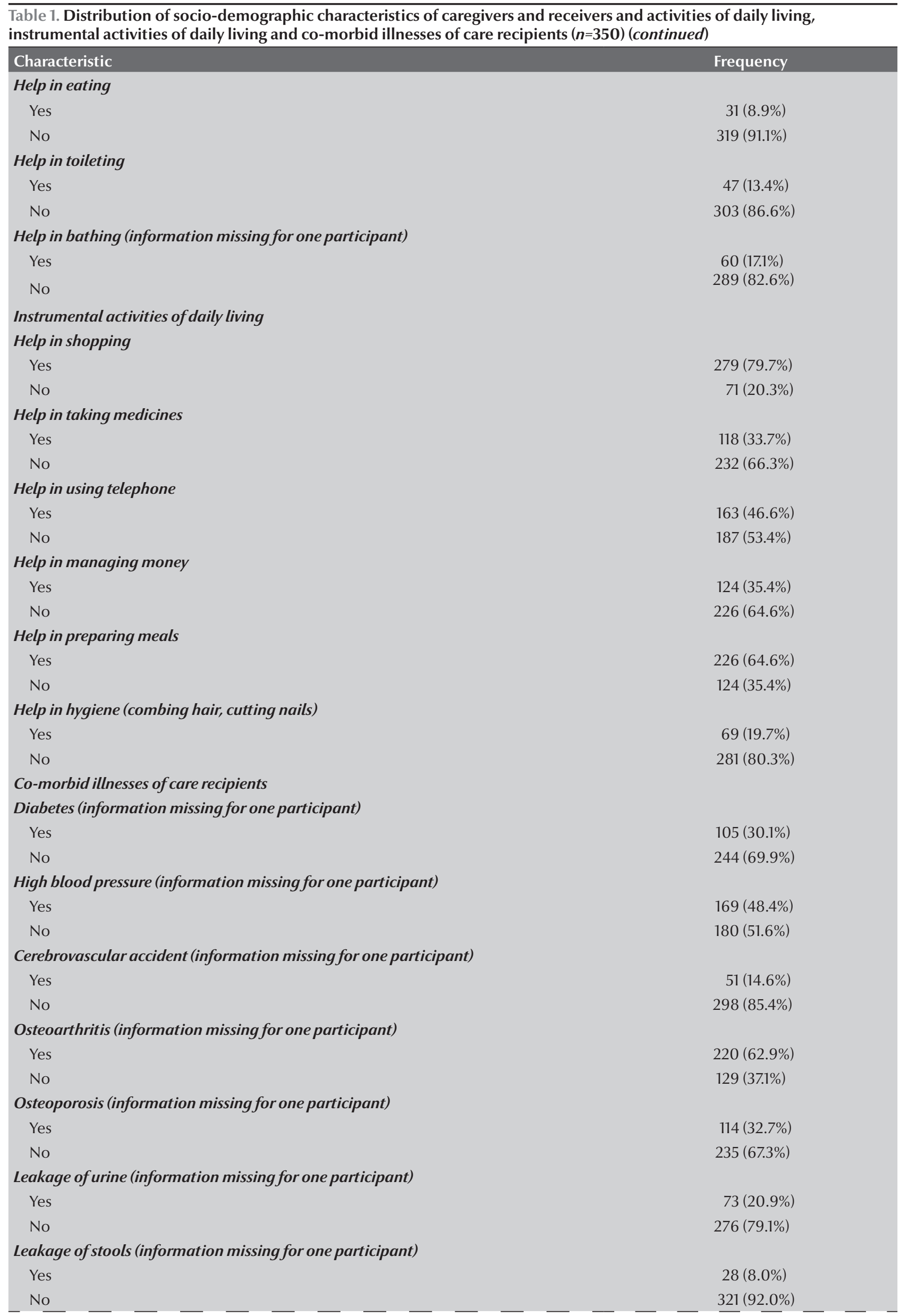




\begin{tabular}{|c|c|}
\hline Characteristic & Frequency \\
\hline \multicolumn{2}{|l|}{ Depression } \\
\hline Yes & $128(36.6 \%)$ \\
\hline No & $222(63.4 \%)$ \\
\hline \multicolumn{2}{|l|}{ Memory loss } \\
\hline Yes & $131(37.4 \%)$ \\
\hline No & $219(62.6 \%)$ \\
\hline \multicolumn{2}{|c|}{ Other chronic illness (information missing for two participants) } \\
\hline Yes & $48(13.7 \%)$ \\
\hline No & $300(85.7 \%)$ \\
\hline \multicolumn{2}{|l|}{ Ambulatory status } \\
\hline Fully mobile & $130(37.1 \%)$ \\
\hline Mobile with help of caregiver & $160(45.7 \%)$ \\
\hline Mobile with an assisted device & $48(13.7 \%)$ \\
\hline Bedbound & $12(3.4 \%)$ \\
\hline \multicolumn{2}{|c|}{ Behavioural problems of care recipients } \\
\hline \multicolumn{2}{|c|}{ Agitation (irritability) } \\
\hline Yes & $183(52.3 \%)$ \\
\hline No & $167(47.7 \%)$ \\
\hline \multicolumn{2}{|l|}{ Aggression (shouting, hitting) } \\
\hline Yes & $121(34.6 \%)$ \\
\hline No & $229(65.4 \%)$ \\
\hline \multicolumn{2}{|l|}{ Verbal abuse } \\
\hline Yes & $71(20.3 \%)$ \\
\hline No & $279(79.7 \%)$ \\
\hline \multicolumn{2}{|l|}{ Low mood (sadness, crying) } \\
\hline Yes & $138(39.4 \%)$ \\
\hline No & $212(60.6 \%)$ \\
\hline \multicolumn{2}{|c|}{ Forgetfulness (information missing for one participant) } \\
\hline Yes & $123(35.2 \%)$ \\
\hline No & $226(64.8 \%)$ \\
\hline \multicolumn{2}{|l|}{ Social withdrawal } \\
\hline Yes & $29(8.3 \%)$ \\
\hline No & $321(91.7 \%)$ \\
\hline \multicolumn{2}{|l|}{ Difficulty in sleeping } \\
\hline Yes & $126(36 \%)$ \\
\hline No & $224(64 \%)$ \\
\hline \multicolumn{2}{|c|}{ Wandering (leaving home without informing caregiver) } \\
\hline Yes & $8(2.3 \%)$ \\
\hline No & $342(97.7 \%)$ \\
\hline \multicolumn{2}{|l|}{ Other behavioural problems } \\
\hline Yes & $20(5.7 \%)$ \\
\hline No & $330(94.3 \%)$ \\
\hline \multicolumn{2}{|l|}{ Perceived care burden } \\
\hline Yes & $176(50.3 \%)$ \\
\hline No & $(49.7 \%)$ \\
\hline
\end{tabular}




\begin{tabular}{|c|c|c|c|}
\hline & Burdened & Not burdened & $P$ \\
\hline Activities of daily living & $n(\%)$ & $n(\%)$ & \\
\hline \multicolumn{4}{|c|}{ Help in changing clothes (information missing for two participants) } \\
\hline Yes & $23(40.4)$ & $34(59.6)$ & 0.10 \\
\hline No & $152(52.2)$ & $139(47.8)$ & \\
\hline \multicolumn{4}{|l|}{ Help in walking } \\
\hline Yes & $23(37.7)$ & $38(62.3)$ & 0.03 \\
\hline No & $153(52.9)$ & $136(47.1)$ & \\
\hline \multicolumn{4}{|l|}{ Help in eating } \\
\hline Yes & $16(51.6)$ & $15(48.4)$ & 0.87 \\
\hline No & $160(50.2)$ & $159(49.8)$ & \\
\hline \multicolumn{4}{|l|}{ Help in toileting } \\
\hline Yes & $19(40.4)$ & $28(59.6)$ & 0.14 \\
\hline No & $157(51.8)$ & $146(48.2)$ & \\
\hline \multicolumn{4}{|c|}{ Help in bathing (information missing for one participant) } \\
\hline Yes & $22(36.7)$ & $38(63.3)$ & 0.01 \\
\hline No & $154(53.3)$ & $135(46.7)$ & \\
\hline \multicolumn{4}{|c|}{ Instrumental activities of daily living } \\
\hline \multicolumn{4}{|c|}{ Help in shopping } \\
\hline Yes & $156(55.9)$ & $123(44.1)$ & 0.00 \\
\hline No & $20(28.2)$ & $51(71.8)$ & \\
\hline \multicolumn{4}{|l|}{ Help in taking medicines } \\
\hline Yes & $63(53.4)$ & $55(46.6)$ & 0.40 \\
\hline No & $113(48.7)$ & $119(51.3)$ & \\
\hline \multicolumn{4}{|l|}{ Help in using telephone } \\
\hline Yes & $87(53.4)$ & $76(46.6)$ & 0.28 \\
\hline No & $89(47.6)$ & $98(52.4)$ & \\
\hline \multicolumn{4}{|l|}{ Help in managing money } \\
\hline Yes & $86(69.4)$ & $38(30.6)$ & 0.00 \\
\hline No & $90(39.8)$ & $136(60.2)$ & \\
\hline \multicolumn{4}{|l|}{ Help in preparing meals } \\
\hline Yes & $135(59.7)$ & $91(40.3)$ & 0.00 \\
\hline No & $41(33.1)$ & $83(66.9)$ & \\
\hline \multicolumn{4}{|l|}{ Help in hygiene } \\
\hline Yes & $25(36.2)$ & $44(63.8)$ & 0.00 \\
\hline No & $151(53.7)$ & $130(46.3)$ & \\
\hline
\end{tabular}

walking and bathing had a significantly higher burden than those who did not $(P<0.05)$. The IADLs with which caregivers were significantly burdened were help with shopping, managing money, preparing meals and ensuring hygiene $(P<0.05)$.

Table 3 shows the correlations between behavioural problems, IADLs, financial impact and total co-morbidity and the caregivers' perception of their burden, for all caregivers and for the 176 who perceived that they were burdened. Behavioural problems were moderately correlated (0.30), overall dependence for IADLs was weakly correlated (0.21), and total co-morbidity was poorly correlated (0.07) (Table 3).

The financial impact of caregiving was strongly correlated (0.79) with caregivers' burden $(P<0.005)$; thus, 28 of the 36 caregivers (77.8\%) who said that their role had a financial impact also considered themselves burdened. Of the 314 caregivers who found no financial impact, 148 (47.1\%) considered themselves burdened.

Binary logistic regression analysis with adjustment for caregiver's age, education, marital status and length of 


\begin{tabular}{|c|c|c|c|c|}
\hline \multirow[t]{2}{*}{ Characteristic } & \multicolumn{2}{|c|}{ All caregivers } & \multicolumn{2}{|c|}{$\begin{array}{l}\text { Caregivers who perceived } \\
\text { a burden }\end{array}$} \\
\hline & Pearson coefficient & $\boldsymbol{P}$ & & \\
\hline Behaviour (sum of behavioural problems) & 0.30 & 0.00 & 0.25 & 0.03 \\
\hline IADLs (sum of IADLs) & 0.21 & 0.00 & 0.29 & 0.00 \\
\hline $\begin{array}{l}\text { Financial impact (sum of subscale items of perceived } \\
\text { caregiver burden scale) }\end{array}$ & 0.79 & 0.00 & 0.60 & 0.00 \\
\hline Total co-morbidity (sum of co-morbid conditions score) & 0.07 & 0.08 & 0.26 & 0.00 \\
\hline
\end{tabular}

care showed that male caregivers were more likely to perceive themselves as burdened (adjusted odds ratio [OR], 1.86; $95 \%$ confidence interval $[\mathrm{CI}]$, 1.03;3.35). Looking after care recipients with sleep disturbances and receiving verbal abuse were also associated with caregiver burden (adjusted OR, 1.84; 95\% CI, 0.96;3.51 and 2.43; 1.05;5.62, respectively). Stroke was also significantly associated with perceived caregiver burden (adjusted OR, 3.03; 95\% CI, 1.34;6.86) (Table 4).

\section{Discussion}

This study fulfilled its objectives by identifying common health problems in elderly people residing in a local community in Pakistan and their association with the burden experienced by their caregivers. The most commonly reported co-morbid conditions were diabetes, hypertension and osteoarthritis. Pakistan is considered to have high rates of diabetes and hypertension (12), and both are risk factors for dementia in the elderly $(13,14)$, possibly accounting for the high rates of memory loss found in our study. Depression was also commonly reported. Depression is linked to dementia in a complex relationship via risk factors, symptoms and functional decline (15).

Most of the elderly in this study did not require help with ADLs, despite a high burden of noncommunicable illness. Their low level of dependence may reflect co-morbid conditions with few complications or of lesser severity. A previous study also found low rates of dependence in elderly people living in the community (7).

The study shows that most care providers are women, consistent with our culture, in which housewives normally assume the role of caregiver, while male members are responsible for earning money outside the home to provide for their families. The situation is similar in other parts of the world (16). A study of 48 low- and middle-income countries also found that women more often assume caregiver roles than men (17).

The relationship between the caregiver and the care receiver was predominantly a spouse or child, as found in previous studies $(18-20)$. Daughters-in-law were the caregivers in a significant number of households in our study, as found in studies in India and the Republic of Korea (21-23). Even among immigrants of Indian and Pakistani descent in the USA, daughters-in-law were the primary care givers, adhering to the cultural norms of their country of origin (24). Family frameworks and structures differ among countries. Daughters almost always leave home after marriage to take over responsibilities in their new home; they therefore are more likely to care for their in-laws and less likely to be the primary caregivers for their own parents. This study did not show whether the burden of caregivers is different when they care for in-laws rather than parents.

Half the caregivers considered that they were burdened. Similar percentages have been found in other studies in the Region (19,25-27). In studies that indicated a higher caregiver burden, the care receivers were more dependent or had more debilitating illnesses. As in previous studies, (18, $21,26,28)$, caregivers for elderly people who were dependent for ADLs perceived a greater burden. In contrast, another study reported that caregiver burden correlated more closely with the needs of the caregiver rather than the functional impairment of the care recipient (27).

As expected, stroke was associated with a higher caregiver burden, probably due to greater physical and cognitive dependence. Problematic behaviour of care recipients, such as verbal abuse and difficulty in sleeping, were also predictors of a greater burden, possibly by creating physical and emotional difficulties for the caregiver. This finding is supported by those of other studies $(24,28-30)$.

The strongest correlation with caregiver burden in our study was financial constraints due to caregiving. In our country, the majority of the population lives below the poverty level, and there is no subsidized health care or discounted prescriptions; therefore, families often bear the cost of health care for the elderly, resulting in financial strain. This factor has also been cited by other authors (31).

Surprisingly, in contrast to other studies in which women considered themselves more heavily burdened, we found that men perceived themselves 


\begin{tabular}{|c|c|c|c|c|}
\hline Characteristic & Unadjusted odds ratio & $95 \% \mathrm{Cl}$ & Adjusted odds ratio ${ }^{1}$ & $95 \% \mathrm{CI}$ \\
\hline Age of care receiver & 0.97 & $0.95 ; 0.99$ & 0.97 & $0.94 ; 1.00$ \\
\hline \multicolumn{5}{|l|}{ Sex of care receiver } \\
\hline Female & 1 & & 1 & \\
\hline Male & 1.27 & $0.83 ; 1.95$ & 1.38 & $0.82,2.38$ \\
\hline \multicolumn{5}{|l|}{ Sex of caregiver } \\
\hline Female & 1 & & 1 & \\
\hline Male & 2.16 & $1.35 ; 3.43$ & $1.90^{*}$ & $1.08 ; 3.36$ \\
\hline \multicolumn{5}{|l|}{ Behavioural problems } \\
\hline Agitation & 1.37 & $0.90 ; 2.09$ & 0.86 & $0.45 ; 1.65$ \\
\hline Aggression & 1.59 & $1.02 ; 2.48$ & 1.36 & $0.63 ; 2.95$ \\
\hline Verbal abuse & 2.27 & $1.32 ; 3.92$ & $2.45^{*}$ & $1.06 ; 5.65$ \\
\hline Depression & 1.37 & $0.89 ; 2.11$ & 1.12 & $0.59 ; 2.12$ \\
\hline Memory loss & 1.83 & $1.17 ; 2.86$ & 0.84 & $0.34 ; 2.03$ \\
\hline Social withdrawal & 1.44 & $0.66 ; 3.12$ & 2.00 & $0.67 ; 6.01$ \\
\hline Difficulty in sleeping & 1.88 & $1.21 ; 2.93$ & $2.00^{*}$ & $1.06 ; 3.77$ \\
\hline Wandering & 0.32 & $0.06 ; 1.61$ & 2.05 & $0.29 ; 14.41$ \\
\hline Others behavioural problems & 0.31 & $0.11 ; 0.87$ & $0.08^{*}$ & $0.02 ; 0.39$ \\
\hline \multicolumn{5}{|l|}{ Co-morbid conditions } \\
\hline Diabetes & 1.32 & $0.83 ; 2.10$ & 1.51 & $0.83 ; 2.75$ \\
\hline Hypertension & 0.87 & $0.57 ; 1.32$ & 0.89 & $0.51 ; 1.56$ \\
\hline Stroke & 1.24 & $0.68 ; 2.25$ & $2.67^{*}$ & $1.20 ; 5.98$ \\
\hline Osteoarthritis & 1.12 & $0.72 ; 1.73$ & 1.55 & $0.87 ; 2.78$ \\
\hline Osteoporosis & 0.23 & $0.14 ; 0.38$ & $0.13^{*}$ & $0.06 ; 0.26$ \\
\hline Urine leaking & 1.09 & $0.65 ; 1.83$ & 1.85 & $0.83 ; 4.07$ \\
\hline Stool leaking & 0.44 & $0.19 ; 1.00$ & $0.20^{*}$ & $0.05 ; 0.69$ \\
\hline Depression & 1.61 & $1.03 ; 2.50$ & 1.61 & $0.82 ; 3.16$ \\
\hline Memory loss & 1.72 & $1.11 ; 2.67$ & 1.85 & $0.82 ; 4.17$ \\
\hline Chronic illness & 0.66 & $0.36 ; 1.23$ & 0.67 & $0.31 ; 1.44$ \\
\hline
\end{tabular}

* $P<0.05$

'Adjusted for caregiver's age, education, marital status and length of caregiving

as more burdened when faced with the challenge of caring for the elderly. This finding is supported by that of another study in Pakistan, in which male caregivers were more "stressed" (32); however, a study in India showed no difference in the stress levels of male and female caregivers (22). In Pakistan, caregiving is a "gender incongruent" role for men, who are the breadwinners and primarily fulfil responsibilities away from home. In-home caregiving is thus harder for men employed out of the home.
The factors associated with caregiver burden raise concern that there are no support systems to offer respite, either in the form of day-care centres or alternative care providers. There are no financial subsidies to help families care for their elderly. An important question is whether caregiver burden results in neglect of the elderly or affects the quality of caregiving in our setting.

\section{Limitations}

While we were able to identify factors associated with caregiver burden, we did not examine its effects. Further studies are required on the impact of this burden on caregivers and caregiving. Another limitation is that this study was conducted in suburban Karachi, and the factors associated with caregiver burden may be different in rural communities. Although financial constraints were a significant source of caregiver burden, detailed socioeconomic data were not obtained, and the source of the financial burden could not be explored.

As family members continue to be the largest source of caregiving for the 
elderly, recognition of their roles and the implications for both the caregiver and the care receiver is essential. Physicians should recognize the needs of caregivers, in addition to providing care to their elderly patients. Both informal and formal support systems should be in place for caregivers. Establishing alternative care services and educational programmes to create awareness of caregiver burden would help in dealing with this issue of increasing importance.

\section{Conclusion}

Caregiver burden is a significant issue for those who care for elderly family members, financial constraints being a strong factor. In view of the growing number of elderly people and the high caregiver burden found in our study, physicians should recognize and advocate for caregivers in order to ease their responsibilities.

Funding: None.

Competing interests: None declared.

\section{References}

1. Global Health Observatory. Pakistan. Geneva: World Health Organization; 2014 (http://apps.who.int/gho/data/node. country.country-PAK?lang=en, accessed 20 March 2015).

2. Health of the elderly. Cairo: WHO Regional Office for the Eastern Mediterranean; 2014 (http://www.emro.who.int/entity/ elderly-health/index.html, accessed 18 February 2015).

3. World report on disability 2011. Geneva: UNICEF; 2011 (http:// www.unicef.org/protection/World_report_on_disability_ eng.pdf, accessed August 2016).

4. Itrat A, Taqui AM, Qazi F, Qidwai W. Family systems: perceptions of elderly patients and their attendents presenting at a university hospital in Karachi, Pakistan. J Pak Med Assoc 2007;57:106.

5. Sabzwari SR, Azhar G. Ageing in Pakistan - a new challenge. Ageing Int 2011;36:423-427.

6. Chan A, Malhotra C, Malhotra R, Rush AJ, Østbye T. Health impacts of caregiving for older adults with functional limitations. Results from the Singapore survey on informal caregiving. J Aging Health 2013;25:998-1012.

7. Inocian EP, Inocian EP, Ysatam EI. The dependency needs in the activities of daily living performance among Filipino elderly. Int Res J Med Med Sci 2014;2:44-50.

8. Thommessen B, Aarsland D, Braekhus A, Oksengaard AR, Engedal K, Laake K. The psychosocial burden on spouses of the elderly with stroke, dementia and Parkinson's disease. Int J Geriatr Psychiatry 2002;17:78-84.

9. Pattanayak RD, Jena R, Tripathi M, Khandelwal SK. Assessment of burden in caregivers of Alzheimer's disease from India. Asian J Psychiatry 2010;3:112-116.

10. Lwanga SK, Lemeshow S. Sample size determination in health studies: a practical manual. Geneva: World Health Organization; 1991.

11. Gupta R. The perceived caregiver burden scale for caregivers of elderly people in India. J Appl Gerontol 2007;26:120-138.

12. Ramachandran A, Ma RC, Snehalatha C. Diabetes in Asia. Lancet 2010;375:408-418.

13. Gorelick PB. Risk factors for vascular dementia and Alzheimer disease. Stroke 2004;35(Suppl 1):2620-2622.

14. Biessels GJ, Staekenborg S, Brunner E, Brayne C, Scheltens P. Risk of dementia in diabetes mellitus: a systematic review. Lancet Neurol 2006;5:64-74.

15. Korczyn AD, Halperin I. Depression and dementia. J Neurol Sci 2009;283:139-142.

16. Pinquart $M$, Sörensen $S$. Gender differences in caregiver stressors, social resources, and health: an updated meta-analysis. Psychol Sci Soc Sci 2006;61:P33-P45.

17. Hosseinpoor AR, Bergen N, Chatterji S. Socio-demographic determinants of caregiving in older adults of low- and middleincome countries. Age Ageing 2013;42:330-338.
18. Yang X, Hao Y, George SM, Wang L. Factors associated with health-related quality of life among Chinese caregivers of the older adults living in the community: a cross-sectional study. Health Qual Life Outcomes 2012;10:1.

19. Abdollahpour I, Noroozian M, Nedjat S, Majdzadeh R. Caregiver burden and its determinants among the family members of patients with dementia in Iran. Int J Prev Med 2012;3:544-551.

20. Morimoto T, Schreiner AS, Asano H. Caregiver burden and health?related quality of life among Japanese stroke caregivers. Age Ageing 2003;32:218-223.

21. Lee M, Yoon E, Kropf NP. Factors affecting burden of South Koreans providing care to disabled older family members. Int J Aging Human Dev 2007;64:245-262.

22. Gupta R, Pillai VK, Levy EF. Relationship quality and elder caregiver burden in India. J Soc Interv Theory Pract 2012;21:39-62.

23. Prince $\mathrm{M}$. Care arrangements for people with dementia in developing countries. Int J Geriatr Psychiatry 2004;19:170-177.

24. Gupta R, Pillai VK. Caregiver burden in South Asian families: a systems theory perspective. J Ethnic Cultur Divers Soc Work 2000:9:41-53.

25. Limpawattana P, Theeranut A, Chindaprasirt J, Sawanyawisuth K, Pimporm J. Caregivers burden of older adults with chronic illnesses in the community: a cross-sectional study. J Community Health 2013;38:40-45.

26. Salama R. Caregiver burden from caring for impaired elderly: a cross-sectional study in rural Lower Egypt. Ital J Public Health 2012;9:e8662-10.

27. Garlo K, O'Leary JR, Van Ness PH, Fried TR. Burden in caregivers of older adults with advanced illness. J Am Geriatr Soc 2010;58:2315-2322.

28. Stolley JM, Reed D, Buckwalter KC. Caregiving appraisal and interventions based on the progressively lowered stress threshold model. Am J Alzheimers Dis Other Demen 2002;17:110-120.

29. Arai $Y$, Kumamoto $K$, Washio $M$, Ueda $T$, Miura H, Kudo K. Factors related to feelings of burden among caregivers looking after impaired elderly in Japan under the long?term care insurance system. Psychiatry Clin Neurosci 2004;58:396-402.

30. Machnicki G, Allegri RF, Dillon C, Serrano CM, Taragano FE. Cognitive, functional and behavioral factors associated with the burden of caring for geriatric patients with cognitive impairment or depression: evidence from a South American sample. Int J Geriatr Psychiatry 2009;24:382-389.

31. Salmon JR, Kwak J, Acquaviva KD, Brandt K, Egan KA. Transformative aspects of caregiving at life's end. J Pain Symptom Manage 2005;29:121-129.

32. Ahmad K. Informal caregiving to chronically ill older family members: caregivers' experiences and problems. S Asian Stud 2012;27:101. 